\title{
A COMPATIBILIDADE DA LEGISLAÇÃO INTERNA COM A CONVENÇÃO INTERNACIONAL SOBRE OS DIREITOS DA PESSOA COM DEFICIÊNCIA NO ACESSO AOS CARGOS PÚBLICOS
}

\section{COMPATIBILITY OF INTERNAL LAW WITH THE INTERNATIONAL CONVENTION ON THE RIGHTS OF PEOPLE WITH DISABILITIES IN ACCESS TO PUBLIC POSITIONS}

\author{
${ }^{1}$ Débora Ribeiro Sá Freire \\ ${ }^{2}$ Danilo Martins Fernandes Drilard
}

\section{RESUMO}

Dentre os direitos garantidos às pessoas com deficiência, destaca-se o acesso aos cargos e empregos públicos por meio de reserva de vagas nos certames, conforme previsto no inciso VIII do artigo 37 da Constituição Federal. O que se pretende investigar neste trabalho como problemática é se há compatibilidade da legislação interna com a Convenção Internacional sobre os Direitos das Pessoas com Deficiência, em especial a questão da reserva de vagas em concursos públicos, verificando a possibilidade de intervenção judicial para que se considere pessoa com deficiência quem não se enquadre na moldura normativa interna.

Palavras-chave: Antinomia normativa, Controle de convencionalidade, E direitos humanos

\begin{abstract}
Among the rights guaranteed to persons with disabilities, there is access to public offices and positions through reserve places in competitions, as provided for in section VIII of Article 37 of the Constitution. What if you want to investigate this work is the issue of national legislation compatible with the International Convention on the Rights of Persons with Disabilities, in particular the issue of the reservation of vacancies in public tenders, checking the possibility of judicial intervention to consider person with disabilities who is not in the internal regulatory framework .
\end{abstract}

Keywords: Normative antinomy, Conventionality control, And human rights

\footnotetext{
${ }^{1}$ Mestranda em Direito pela Universidade Veiga de Almeida - UVA, Rio de Janeiro (Brasil).

E-mail: deborasafreire@hotmail.com

${ }^{2}$ Bacharel em Direito pela Centro Universitário de Barra Mansa - UBM, Rio de Janeiro (Brasil). Procurador pela Prefeitura Municipal de Volta Redonda - PMVR, Rio de Janeiro (Brasil). E-mail: danilodrilard@gmail.com
} 


\section{INTRODUÇÃO}

A Convenção Internacional sobre os Direitos das Pessoas com Deficiência e seu Protocolo Facultativo foram as primeiras normas internacionais a serem incorporadas ao ordenamento jurídico na forma prevista no $\S 3^{\circ}$ do artigo $5^{\circ}$ da Constituição Federal, sendo, portanto, equivalente às emendas constitucionais. Anteriormente a este importante instrumento de proteção internacional, o Estado brasileiro havia ratificado outros tratados e convenções que previam direitos e compromissos em relação a esse grupo minoritário, além de diversas normas na Constituição e na legislação esparsa. Dentre os direitos garantidos às pessoas com deficiência, destaca-se o acesso aos cargos e empregos públicos por meio de reserva de vagas nos certames, conforme previsto no inciso VIII do artigo 37 da Constituição Federal.

A problemática investigada é se há compatibilidade da legislação interna com a Convenção Internacional sobre os Direitos das Pessoas com Deficiência, em especial a questão da reserva de vagas em concursos públicos, verificando a possibilidade de intervenção judicial para que se considere pessoa com deficiência quem não se enquadre na moldura normativa interna.

Justifica-se o presente trabalho porque, o que se verifica, inicialmente, é que o Poder Judiciário tem adotado uma postura interpretativa restritiva, como por exemplo, na edição recente da Súmula 552 pelo Superior Tribunal de Justiça, que estabelece que "O portador de surdez unilateral não se qualifica como pessoa com deficiência para o fim de disputar as vagas reservadas em concursos públicos".

O objetivo geral da pesquisa é responder a problemática investigada e analisar o conflito de normas para adequar o conceito de pessoa com deficiência.

Os objetivos específicos são:

(i) a partir da hermenêutica constitucional pretende-se elucidar se a legislação interna está em sintonia com a proteção pretendida pela Convenção; e

(ii) bem como se o Judiciário pode intervir nas relações entre candidatos e Administração Pública para permitir, no caso concreto, o benefício da reserva de vagas a quem não se enquadra na definição de pessoa com deficiência prevista na legislação interna, utilizando-se do denominado controle de convencionalidade.

A abordagem metodológica da pesquisa cinge-se em:

(i) fazer a revisão literária integrada; 
(ii) a obtenção de dados secundários para entender a dinâmica dos concursos públicos e a reserva de vagas para pessoas com deficiência; e

(iii) pesquisa legislativa e jurisprudencial.

Ressalta-se que a dimensão espacial da pesquisa de campo abrange os representativos municípios de Volta Redonda, Barra Mansa e de Resende e a temporal da pesquisa inicia-se em outubro de 2015e concluí-se em fevereiro de 2016.

A Pesquisa de Campo foi aplicada a uma categoria de sujeitos de direitos. As perguntas tratam acerca das condições, características e legalidade da reserva de vagas nos concursos Públicos para pessoas com deficiência.

\section{A) Abordagem teórica - Revisão Bibliográfica:}

À época, foram escolhidos na categoria de marcos teóricos da Pesquisa de Campo os autores abaixo indicados que se encontram na Biblioteca Dr. Ayres de Azevedo situada na floresta da Cicuta, na cidade de Volta Redonda, fundada em 1962.

Os livros temáticos foram lidos e fichados pelos pesquisadores. Após, foram debatidos com a Orientadora, com a finalidade de auxiliar a elaboração do questionário pelos pesquisadores. Tal documento se encontra indicado no item B deste trabalho foi apresentado aos membros do Poder Executivo para a realização da pesquisa de campo:

(i) Maria Sylvia Zanella Di Pietro, em sua obra Direito Administrativo para entender a reserva de vagas nos concursos públicos;

(ii) Flávia Piovesan, em Direitos Humanos e o Direito Constitucional Internacional, com o fim de entender sobre os direitos das pessoas com deficiência previstos na Convenção sobre os Direitos das Pessoas com Deficiência;

(iii) Claudio Pereira de Souza Neto e Daniel Sarmento, no livro Direito Constitucional: Teoria, história e métodos de trabalho, com a finalidade de compreender a hermenêutica constitucional.

(iv) Valerio de Oliveira Mazzuoli, no livro Tratados Internacionais de Direitos Humanos e Direito Interno, para compreender o controle de convencionalidade.

Da leitura destes autores acima aludidos, extraíram-se os conceitos básicos, que subsidiaram a análise da hipótese que se apresenta na pesquisa. Ressalva-se que ocorreu, também, a leitura das referências bibliográficas citadas no curso do artigo. 


\section{B) Abordagem dos Dados Secundários:}

Os dados estatísticos apresentados neste artigo foram extraídos de órgãos oficiais ou de pesquisa, preferencialmente do Governo, verbis:

(i) BRASIL.Lei $\mathrm{n}^{\circ} 13.146$ de 6 de julho de 2015.

(ii) Convenção Internacional Sobre os Direitos das Pessoas com Deficiência Decreto Legislativo n $^{\circ} 186$, de 9 de julho de 2008;

(iii) STJ - Superior Tribunal de Justiça;

(iv) TST - Tribunal Superior do Trabalho.

\section{BREVE HISTÓRICO SOBRE A RESERVA DE CARGOS E EMPREGOS PÚBLICOS PARA AS PESSOAS COM DEFICIÊNCIA}

O Direito Internacional dos Direitos Humanos, bem como a Constituição Federal de 1988, erigem um sistema especial de proteção dos grupos socialmente vulneráveis, num processo denominado especificação do sujeito de direito, que pode ser entendido na proteção legislativa direcionada ao indivíduo considerado em suas peculiaridades dentro do contexto histórico e social.

A propósito, ao lado do sistema geral de proteção, organiza-se o sistema especial de proteção, que adota como sujeito de direito o indivíduo historicamente situado, isto é, o sujeito de direito „concreto ${ }^{\text {ee }}$, na peculiaridade e particularidade de suas relações sociais. No caso brasileiro, o processo de especificação do sujeito de direito ocorreu fundamentalmente com a Constituição brasileira de 1988, que, por exemplo, traz capítulos específicos dedicados à criança, ao adolescente, ao idoso, aos índios, bem como dispositivos constitucionais específicos voltados às mulheres, à população negra, às pessoas com deficiência etc. Consolida-se, dessa forma, tanto no Direito Internacional como no Direito brasileiro, o valor da igualdade, com o respeito à diferença e à diversidade (PIOVESAN, 2012, p. 242).

Nesse processo de especificação do sujeito de direito, no que tange às pessoas com deficiência, existe profícua legislação internacional e interna, sendo que se pretende demonstrar as normas destinadas à inserção desse grupo nos cargos e empregos públicos, por meio de reserva de vagas nos concursos públicos.

Feitas essas breves considerações, passa-se à análise de como se deu a especificação dos direitos das pessoas com deficiência no plano internacional e interno, no que se refere à inserção desse grupo no serviço público. 


\subsection{A especificação em âmbito internacional sobre o direito das pessoas com deficiência e as cotas no serviço público}

No processo histórico de especificação dos direitos das pessoas com deficiência foram produzidas declarações de direitos e convenções. Para fins deste estudo serão evidenciados os direitos relacionados ao acesso aos cargos e empregos públicos.

Embora não fizesse referência expressa ao acesso ao serviço público, a Declaração dos Direitos de Pessoas com Deficiência Mental, aprovada pela Resolução da ONU n ${ }^{\circ}$ 2.856, de 20 de dezembro de 1971, por meio de seu artigo 3, estabelecia que o deficiente mental tinha direito, "na medida de suas possibilidades, a exercer uma atividade produtiva ou alguma ocupação útil". No mesmo sentido foi a previsão contida na Declaração dos Direitos das Pessoas Portadoras de Deficiência, de 9 de dezembro de 1975.

Com o advento das Normas sobre Equiparação de Oportunidades, por meio da Resolução da ONU nº 48/96, de 20 de dezembro de 1993, verifica-se previsão expressa sobre a inclusão das pessoas com deficiência no serviço público, conforme se verifica da Norma 7 , que estabelece: "Em sua capacidade como empregadores, os Países-Membros devem criar condições favoráveis para o emprego de pessoas com deficiência no setor público".

Por meio do Decreto $\mathrm{n}^{\mathrm{o}} 3.956$, de 08 de outubro de 2001, se incorporava ao ordenamento jurídico pátrio a Convenção Interamericana para a Eliminação de Todas as Formas de Discriminação contra as Pessoas Portadoras de Deficiência, a qual obrigava os Estados a adotarem diversas medidas com o fim de eliminar a discriminação desse grupo, dentre as quais constava a previsão de promoção do emprego.

De especial relevância no âmbito internacional e interno é a Convenção Sobre os Direitos das Pessoas com Deficiência e seu protocolo facultativo, aprovados pela Resolução da ONU A/61/611 de 6 de dezembro de 2006, sendo a primeira legislação internacional incorporada ao ordenamento nacional na forma prevista no $\S 3^{\circ}$ do artigo $5^{\circ}$ da Constituição Federal de 1988 , equiparando-se à emenda constitucional. Verifica-se dessa convenção, em seu artigo 27, item 1, letra "g", que dentre as medidas a serem adotadas consta a de empregar pessoas com deficiência no setor público.

Verifica-se que a convenção integra o que se denomina "bloco de constitucionalidade", que pode ser entendido como o conjunto de normas a que se reconhece hierarquia constitucional num dado ordenamento. Tais normas, ainda que não figurem no documento constitucional, podem ser tomadas como parâmetro para o exercício do controle de constitucionalidade (NETO e SARMENTO, 2015, p .47). 


\subsection{A legislação interna sobre a reserva de cargos e empregos públicos para as pessoas com deficiência}

Os dispositivos específicos dos direitos das pessoas com deficiência somente puderam ser observados a partir de 1978, com a edição da Emenda Constitucional n ${ }^{\circ}$ 12/78, que representou um marco na defesa desse grupo (PIOVESAN, 2012, p. 354). Cumpre frisar que esta emenda ainda não havia inserido a reserva de vagas no concurso público, o que somente veio a ocorrer com a Constituição Federal de 1988, em seu artigo 37, inciso VIII.

No curso do processo de especificação do sujeito de direito, um ano após a vigência da Constituição de 1988 é promulgada a Lei no 7.853, de 24 de outubro de 1989, que dispõe sobre o apoio às pessoas com deficiência, disciplinando ainda a tutela jurisdicional de interesses coletivos ou difusos desse grupo e define tipos penais. Consta da lei a previsão de reserva de vagas nas entidades da Administração Pública (artigo 2º parágrafo único, inciso III, alínea "d").

A Lei 7.853/1989 foi regulamentada pelo Decreto $\mathrm{n}^{\mathrm{o}} 3.298$ de 20 de dezembro de 1999, o qual dispôs sobre a Política Nacional para a Integração da Pessoa Portadora de Deficiência, que em seu artigo $37, \S 1^{\circ}$, garante reserva mínima de $5 \%$ das vagas do concurso às pessoas com deficiência. Os Estados e Municípios que não tenham norma sobre a matéria estão sujeitos à observância do mínimo fixado pelo Decreto n ${ }^{\circ} 3.398 / 99$, que constitui norma de âmbito nacional (DI PIETRO, 2011, p. 545).

No âmbito da União, a Lei $\mathrm{n}^{\circ}$ 8.112, de 11 de dezembro de 1990, estabelece em seu artigo $5^{\circ}, \S 2^{\circ}$, que para as pessoas com deficiência "serão reservadas até $20 \%$ (vinte por cento) das vagas oferecidas no concurso". Para os concursos da Magistratura em todos os ramos do Poder Judiciário nacional, o Conselho Nacional de Justiça (CNJ) editou a Resolução $\mathrm{n}^{\circ}$ 75, de 12 de maio de 2009, com a previsão de reserva mínima de 5\% do total das vagas para os candidatos habilitados como pessoa com deficiência.

Recentemente entrou em vigor a Lei no 13.146, de 6 de julho de 2015, que instituiu a Lei Brasileira de Inclusão da Pessoa com Deficiência, também denominada de Estatuto da Pessoa com Deficiência, a qual não dispôs expressamente sobre a reserva de vagas em concurso público, prevalecendo, portanto, as disposições legais e regulamentares mencionadas acima. 


\subsection{A definição de pessoa com deficiência à luz da Convenção Internacional sobre os} Direitos das Pessoas com Deficiência e sua (in)compatibilidade com a legislação interna

A definição de pessoa com deficiência é de fundamental importância, mormente quanto à reserva de vagas em concursos públicos, uma vez que a Administração Pública necessita de critérios objetivos para aferir o preenchimento dos requisitos para o candidato se beneficiar da reserva de vagas. Some-se, ainda, que o concurso público atende aos princípios da igualdade e impessoalidade. Sendo assim, caso não se tenha critérios claros, é possível que fiquem excluídos da proteção legal quem dela necessita, ao mesmo tempo em que se corre o risco de estendê-la a quem não faz jus.

Estabelecida essa premissa, deve-se verificar a definição de pessoa com deficiência prevista na convenção em seu artigo 1:

"Pessoas com deficiência são aquelas que têm impedimentos de longo prazo
de natureza física, mental, intelectual ou sensorial, os quais, em interação
com diversas barreiras, podem obstruir sua participação plena e efetiva na
sociedade em igualdades de condições com as demais pessoas."

Como se constata, a definição de pessoa com deficiência prevista na Convenção é aberta e abrangente, uma vez que, ao lado da deficiência em si, agrega o ambiente econômico e social no qual se insere o destinatário da proteção, ao se referir às interações com diversas barreiras.

Ante essa peculiaridade, a própria Convenção reconhece ser a deficiência um conceito em construção, que resulta da interação de pessoas com restrições e barreiras que impedem a plena e efetiva participação na sociedade em igualdade com os demais. A deficiência deve ser vista como o resultado da interação entre indivíduos e seu meio ambiente e não como algo que reside intrinsecamente no indivíduo (PIOVESAN, 2012, p. 124).

\section{CRITÉRIOS DE SOLUÇÃO DE CONFLITOS NORMATIVOS - A QUESTÃO DA DEFINIÇÃO DE PESSOA COM DEFICIÊNCIA PARA FINS DE RESERVA DE CARGOS E EMPREGOS PÚBLICOS}

Os tratados e convenções sobre direitos humanos representam mais um paradigma, ao lado da Constituição, de verificação da validade da legislação infraconstitucional, uma vez que podem ser material e formalmente constitucionais (quando aprovados na forma do $\S 3^{\circ}$ do artigo $5^{\circ}$ da Constituição Federal de 1988) ou podem ter natureza normativa supralegal (quando aprovados por maioria simples dos membros do Congresso Nacional). 
A Convenção Internacional sobre os Direitos das Pessoas com Deficiência trouxe para o ordenamento jurídico pátrio um conceito aberto de pessoa com deficiência, o qual, segundo consta na própria norma internacional, é um conceito em evolução. Ademais, a regulamentação interna atual possui definição taxativa das deficiências, sem considerar as barreiras enfrentadas por essas pessoas em vista do contexto social, econômico e cultural no qual estão inseridas. Assim, se pode inferir que haveria uma possível antinomia entre a Convenção e a legislação interna.

As divergências a respeito de quais deficiências habilitariam o candidato a concorrer às vagas reservadas têm ecoado na jurisprudência. Sobre o tema o Superior Tribunal de Justiça editou dois enunciados consubstanciados nas súmulas 377 e 552 . A súmula 377 estabelece que "o portador de visão monocular tem direito de concorrer, em concurso público, às vagas reservadas aos deficientes", ao passo que a súmula 552 dispõe que "o portador de surdez unilateral não se qualifica como pessoa com deficiência para o fim de disputar as vagas reservadas em concursos públicos".

Recentemente o órgão especial do Tribunal Superior do Trabalho entendeu que a surdez unilateral qualifica a pessoa como deficiente para fins de reserva de vagas, diversamente do posicionamento sumulado pelo Superior Tribunal de Justiça. Trata-se do Recurso Ordinário no TST-RO-54-83.2015.5.12.0000, cuja ementa é a seguinte:

"RECURSO ORDINÁRIO - MANDADO DE SEGURANÇA -
CONCURSO PÚBLICO - PERDA AUDITIVA UNILATERAL -
INCLUSÃO NA LISTA DE CANDIDATOS COM DEFICIÊNCIA -
DIREITO LÍQUIDO E CERTO
A jurisprudência desta Eg. Corte - interpretando de forma harmônica as
disposições do Decreto $\mathrm{n}^{\circ}$ 3.298/99, em conjunto com as disposições legais e
constitucionais pertinentes, bem como com o disposto na Convenção
Internacional sobre os Direitos das Pessoas com Deficiência - tem reconhecido
o direito de os candidatos com perda auditiva unilateral concorrerem, em
concurso público, às vagas destinadas às pessoas com deficiência. Precedentes.
Recurso Ordinário a que se dá provimento."

Considerando essa possível antinomia, cumpre estabelecer qual o melhor critério para solucioná-la. Inicialmente, consigna-se que enquanto não seja editada nova regulamentação para fins de definição de pessoa com deficiência, na forma do artigo $2^{\circ}$, parágrafos primeiro e segundo do Estatuto da Pessoa com Deficiência (Lei $\mathrm{n}^{\circ}$ 13.146/2015), deve-se utilizar como parâmetro o Decreto 3.298/99. Isso porque ele traz critérios objetivos que auxiliam a Administração Pública na realização do certame, conferindo previsibilidade e segurança jurídica. 
Embora se deva aplicar o referido decreto, não se pode pretender que ele encerre todas as deficiências passíveis de habilitar o candidato a concorrer às vagas destinadas às pessoas com deficiência. O que deve existir é a coordenação entre o referido decreto e a Convenção, de forma que as normas possam estabelecer diálogo sempre buscando privilegiar os direitos da pessoa com deficiência. O diálogo das fontes permite que se inclua sistematicamente, nas relações entre o direito internacional dos direitos humanos e o direito interno, a "coordenação solidária” e se afaste de vez o ,antagonismo disfuncional”, a permitir que uma fonte comunique à outra aquilo que entende viável, a fim de resolver a antinomia no caso concreto; e o juiz escuta o que tais fontes dizem, coordena esse "diálogo" em sua aplicação prática e, finalmente, decide com justiça o caso concreto (MAZUOLLI, 2010, p. 135).

Importante salientar que consta a denominada cláusula de diálogo na própria Convenção Internacional sobre o Direito das Pessoas com Deficiência, que em seu artigo 4, item 4 estabelece:

4. Nenhum dispositivo da presente Convenção afetará quaisquer disposiçães mais propícias
à realização dos direitos das pessoas com deficiência, as quais possam estar contidas na
legislação do Estado Parte ou no direito internacional em vigor para esse Estado. Não haverá
nenhuma restrição ou derrogação de qualquer dos direitos humanos e liberdades
fundamentais reconhecidos ou vigentes em qualquer Estado Parte da presente Convenção, em
conformidade com leis, convenções, regulamentos ou costumes, sob a alegação de que a
presente Convenção não reconhece tais direitos e liberdades ou que os reconhece em menor
grau.

No mesmo sentido é a previsão contida no Estatuto da Pessoa com Deficiência (Lei no 13.146/2015), que dispõe em seu artigo 121 e parágrafo único:

Art. 121. Os direitos, os prazos e as obrigações previstos nesta Lei não excluem os já estabelecidos em outras legislações, inclusive em pactos, tratados, convenções e declarações internacionais aprovados e promulgados pelo Congresso Nacional, e devem ser aplicados em conformidade com as demais normas internas e acordos internacionais vinculantes sobre a matéria. Parágrafo único. Prevalecerá a norma mais benéfica à pessoa com deficiência.

Sendo assim, a partir do Decreto $\mathrm{n}^{\circ} 3.298 / 1999$ se busca a definição de pessoa com deficiência, uma vez que não há dúvidas de que as hipóteses elencadas são indiscutíveis, pois aquele que se enquadrar dentro de uma daquelas definições poderá participar do concurso público habilitando-se às vagas reservadas. Todavia, quando a definição constante for insuficiente, uma vez que excludente, deixando desamparada pessoa que efetivamente possua uma deficiência, como, v.g., reconheceu o Tribunal Superior do Trabalho no caso de surdez unilateral e o Superior Tribunal de Justiça no caso da visão monocular, deverá se buscar na Convenção Internacional sobre os Direitos da Pessoa com Deficiência o fundamento para garantir à pessoa com a deficiência não prevista no regulamento o direito de concorrer às vagas reservadas. 


\section{O DIREITO DAS PESSOAS COM DEFICIÊNCIA AO ACESSO AOS CARGOS E EMPREGOS PÚBLICOS - DESAFIOS E PERSPECTIVAS.}

Os concursos públicos para ingresso no serviço público visam garantir os princípios constitucionais-administrativos da igualdade e impessoalidade e, ao mesmo tempo, garantir a boa administração e eficiência na medida em que se busca selecionar aqueles com melhor aptidão para o exercício do cargo ou emprego. No que tange às pessoas com deficiência, visando garantir a igualdade material, a Constituição Federal de 1988 prevê a reserva de vagas:

Art. 37. A administração pública direta e indireta de qualquer dos Poderes da União, dos Estados, do Distrito Federal e dos Municípios obedecerá aos princípios de legalidade, impessoalidade, moralidade, publicidade e eficiência e, também, ao seguinte:

VIII - a lei reservará percentual dos cargos e empregos públicos para as pessoas portadoras de deficiência e definirá os critérios de sua admissão;

\subsection{A superação do conflito normativo a partir da hermenêutica constitucional - análise dos princípios da máxima efetividade dos direitos fundamentais e da proibição da proteção insuficiente}

A Convenção Internacional sobre os Direitos da Pessoa com Deficiência estabelece diversos direitos das pessoas com deficiência. Entretanto, para que tenha aplicabilidade, muitos direitos reconhecidos demandam regulamentação interna por parte dos Estados, a se iniciar pela própria definição de pessoa com deficiência e, para isso, num primeiro momento exige-se a atuação do legislador para regulamentar e conformar o conteúdo dos direitos das pessoas com deficiência.

No que se refere à definição de pessoa com deficiência, na tarefa regulatória o Estado deverá, dentro de um universo de deficiências existentes, elencar aquelas que atendam e estejam em conformidade com a definição da Convenção. O Estatuto da Pessoa com Deficiência, reconhecendo a dificuldade na definição de pessoa com deficiência, previu a possibilidade de análise por critério biopsicossocial a ser feita por equipe multiprofissional e interdisciplinar, destacando os aspectos a serem considerados, conforme se verifica do $\S 1^{\circ}$, do artigo $2^{\circ}$, abaixo transcrito:

Art. $2^{\circ}$ Considera-se pessoa com deficiência aquela que tem impedimento de longo prazo de natureza física, mental, intelectual ou sensorial, o qual, em interação com uma ou mais barreiras, pode obstruir sua participação plena e efetiva na sociedade em igualdade de condições com as demais pessoas.

$\S 1^{\circ}$ A avaliação da deficiência, quando necessária, será biopsicossocial, realizada por equipe multiprofissional e interdisciplinar e considerará:

I - os impedimentos nas funções e nas estruturas do corpo; II - os fatores

socioambientais, psicológicos e pessoais; 
III - a limitação no desempenho de atividades; e

IV - a restrição de participação.

$\S 2^{\circ}$ O Poder Executivo criará instrumentos para avaliação da deficiência.

Todavia, o $\$ 1^{\circ}$ do artigo $2^{\circ}$ do Estatuto das Pessoas com Deficiência está com sua vigência suspensa em até dois anos, conforme previsto no artigo 124 da mesma lei e, enquanto não seja editada nova regulamentação, as disposições do Decreto 3.298/1999 continuam em vigor, as quais não atendem de forma plena a definição de pessoa com deficiência prevista na Convenção. Assim, verifica-se que atualmente existe um possível conflito entre a Convenção Internacional sobre os Direitos da Pessoa com Deficiência e o Decreto nº 3298/1999, e é possível que a futura norma regulamentadora seja insuficiente na definição de pessoa com deficiência.

Pelo princípio da máxima efetividade das normas constitucionais definidoras de direitos fundamentais, não é possível que se invoque a ausência ou insuficiência de regulamentação interna para excluir da proteção pretendida pela Convenção pessoas com deficiência que dela necessitam. Deve-se, ao contrário, extrair da própria norma da Convenção - que se equivale à emenda constitucional, integrando o bloco de constitucionalidade - o fundamento para a garantia dos direitos da pessoa com deficiência, de forma a conferir-lhe a máxima efetividade, buscando realizar tanto quanto possível na realidade social os valores contidos na norma (BARROSO, 2009. p. 156).

É necessário, no entanto, cautela ao se buscar o fundamento na própria Convenção para a verificação se o candidato se qualifica como pessoa com deficiência para fins de se beneficiar da reserva de vagas em concurso público. Isso porque, como já dito, não se pode alargar em demasia a definição, sob pena de, ao invés de promover a igualdade, criar-se mais desigualdade, ao permitir que se beneficie da reserva de vagas quem dela efetivamente não precisa.

Entretanto, é possível que o legislador ou mesmo a Administração Pública em sua tarefa regulatória, crie critérios desproporcionais ao elencarem as deficiências, o que pode excluir da proteção pretendida pela norma internacional pessoas com deficiência que dela efetivamente necessitam. Nesse caso, deve-se lançar mão do princípio da proporcionalidade no sentido de proibição de proteção insuficiente ou deficiente, porque é papel do Estado atuar positivamente para proteger e promover direitos e objetivos comunitários, e que ele ofende a ordem jurídica e a Constituição não apenas quando pratica excessos, intervindo de maneira exagerada ou indevida nas relações sociais, mas também quando deixa de agir em prol dos 
direitos fundamentais ou de outros bens jurídicos relevantes, ou o faz de modo insuficiente (NETO e SARMENTO, 2015, p. 482).

Portanto, ao lado do princípio da máxima efetividade dos direitos fundamentais, o princípio da proibição da proteção insuficiente revela-se como poderoso instrumento hermenêutico apto a subsidiar a superação de antinomias entre a norma internacional e a legislação interna, principalmente quando se está perante direitos e princípios fundamentais, que são dotados de densa carga valorativa, e, por isso mesmo, dependem de atuação do legislador para sua conformação e aplicabilidade.

Conclui-se, portanto, que na superação das antinomias entre a Convenção e a legislação interna deverá ser verificado se esta é insuficiente para se alcançar a máxima efetividade daquela. Se assim o for, deverá ser conferida interpretação que corrija a deficiência na regulamentação interna, aplicando-se o princípio da proporcionalidade, tendo como finalidade conferir a máxima efetividade à Convenção Internacional sobre os Direitos das Pessoas com Deficiência. No que tange ao objeto deste estudo, quando determinada deficiência não estiver elencada na legislação interna para fins de habilitação no concurso para o benefício de reserva de vagas, deverá ser verificado se esta exclusão é ou não proporcional (proibição da proteção deficiente), bem como se atende aos valores e princípios da Convenção (princípio da máxima efetividade).

\subsection{O controle de convencionalidade - a possibilidade de intervenção judicial para a efetividade da Convenção Internacional sobre os Direitos da Pessoa com Deficiência para a garantia de acesso aos cargos e empregos públicos}

Os tratados e convenções sobre direitos humanos representaram uma reconfiguração na estrutura normativa do Estado brasileiro, uma vez que, a partir da Constituição Federal de 1988, ingressam no ordenamento jurídico com o status de normas materialmente constitucionais. Quanto ao quorum de ratificação, o Supremo Tribunal Federal entendeu que os tratados e convenções sobre direitos humanos ratificados pelo Congresso Nacional por maioria simples de seus membros são dotados de supralegalidade, não existindo dúvidas de que os aprovados na forma do $\S 3$ do artigo $5^{\circ}$ da Constituição Federal de 1988 são equivalentes às emendas constitucionais. De qualquer modo - sejam equivalentes às emendas constitucionais, sejam supralegais -, os tratados e convenções de direito direitos humanos são hierarquicamente superiores à legislação ordinária e complementar.

Portanto, doravante, não só a Constituição, mas também os tratados de direitos humanos são paradigmas de aferição da validade das leis, por meio do denominado controle 
de convencionalidade, que consiste na compatibilidade do direito doméstico com os tratados internacionais de direitos humanos em vigor no País, que é complementar e coadjuvante (jamais subsidiário) do conhecido controle de constitucionalidade. O controle de convencionalidade tem por finalidade compatibilizar verticalmente as normas domésticas (as espécies de leis, lato sensu, vigentes no País) com os tratados internacionais de direitos humanos ratificados pelo Estado e em vigor no território nacional (MAZUOLLI, 2010, p. 208).

Insta destacar que este controle de convencionalidade pode se dá pela via concentrada e pela via difusa, sendo que na primeira forma somente é cabível em face dos tratados e convenções sobre direitos humanos aprovados na forma do $\S 5^{\circ}$, do artigo $5^{\circ}$ da CRFB/1988, uma vez que, por se equiparar às emendas constitucionais, integra o denominado "bloco de constitucionalidade".

No que tange aos tratados e convenções sobre direitos humanos com natureza normativa supralegal, ou seja, aqueles que não tenham sido aprovados na forma do $\S 3^{\circ}$ do artigo $5^{\circ}$ da Constituição, servem como parâmetro para o controle difuso de convencionalidae, a ser exercido por qualquer órgão jurisdicional.

Assim, por meio do controle de convencionalidade é legítima a intervenção do Poder Judiciário nas relações jurídicas entre os candidatos e a Administração Pública, verificando a compatibilidade da legislação interna com a Convenção Internacional sobre os Direitos da Pessoa com Deficiência. Até porque, enquanto compromisso assumido pelo Estado brasileiro perante a sociedade internacional, os tratados de direitos humanos exigem a atuação de todos os Poderes para sua aplicação e plena eficácia. Portanto, ao Poder Judiciário cumpre importante papel na concretização dos direitos humanos incorporados ao ordenamento jurídico pelos tratados e convenções de direitos humanos.

Verificada a possibilidade de intervenção do Poder Judiciário para concretizar os direitos previstos nos tratados e convenções sobre direitos humanos, por meio do controle de convencionalidade, cumpre agora delimitar essa atuação, de forma a garantir racionalidade à atividade jurisdicional.

Demonstrou-se linhas acima que o Poder Judiciário já se pronunciou a respeito da definição de pessoa com deficiência contida atualmente no Decreto 3.298/1999, estendendo a possibilidade de habilitação como pessoa com deficiência para candidatos que não se enquadram na definição de referida norma (como no caso da surdez unilateral e da visão monocular). 
Atualmente o Estatuto da Pessoa com Deficiência estabelece que, quando for necessário, a verificação da deficiência poderá ser feita por avaliação biopsicossocial a ser realizada por equipe multiprofissional e interdisciplinar, elencando os fatores a serem considerados, que são: a) os impedimentos nas funções e nas estruturas do corpo; b) os fatores socioambientais, psicológicos e pessoais; c) a limitação no desempenho de atividades; e d) a restrição de participação (artigo $2^{\circ}, \S 1^{\circ}$, da Lei $n^{\circ} 13.146 / 2015$ ). No $\S 2^{\circ}$ do artigo $2^{\circ}$ do Estatuto há dispositivo expresso determinando ao Poder Executivo a criação de instrumentos para a avaliação da deficiência.

É possível inferir que a própria lei vislumbra a dificuldade de se delimitar quais deficiências devem ser consideradas para fins da proteção da norma, prevendo a possibilidade de avaliação por equipe multiprofissional e interdisciplinar na qual se avaliará aspectos sociais, econômicos e culturais, de forma a atender a definição de pessoa com deficiência prevista na Convenção.

Assim, quando o Judiciário for instado a se pronunciar em um caso concreto sobre o enquadramento da pessoa como deficiente para fins de reservas de vagas, deverá levar em consideração os fatores elencados pela Lei $n^{\circ} 13.146 / 2015$, no $\S 1^{\circ}$ do artigo $2^{\circ}$. É de salutar importância também a produção de prova técnica pericial, sempre que possível seguindo os parâmetros do Estatuto da Pessoa com Deficiência, ou seja, a ser realizada por equipe multiprofissional e interdisciplinar. Ao assim proceder, o Poder Judiciário terá mais segurança ao proferir a decisão judicial, podendo assim consolidar entendimento jurisprudencial que reconheça outras deficiências além das previstas na legislação interna, podendo influenciar na produção de regulamentação futura.

Não se pode olvidar também sobre as ações coletivas e a ação civil pública, que podem ser instrumentos judiciais eficazes para garantir a reserva de vagas a grupos de pessoas com deficiência que estejam excluídas da legislação interna. A atuação do Poder Judiciário também se justiça pelo necessário diálogo das fonte e pelo princípio pro homine.

$\mathrm{O}$ diálogo das fontes em cotejo com o princípio pro homine visa superar os antigos métodos de resolução de antinomias normativas, que consistem em: a) hierárquico, a lei de hierarquia superior prevalece sobre a de menor hierarquia; b) temporal: lei posterior revoga a lei anterior; e c) especialidade: lei especial derroga a lei geral. Isso porque na seara dos direitos humanos deve-se privilegiar a norma mais favorável ao indivíduo destinatário da proteção, carecendo de sentido, portanto, os métodos tradicionais de resolução de conflitos normativos. 
Deve-se perquirir, neste momento, se não está o princípio internacional pro homine a integrar os princípios adotados pela Constituição. Segundo entendemos, quer no plano do direito interno, quer no plano internacional, o princípio internacional pro homine pode ser considerado um princípio geral de direito. Seu conteúdo expansivo atribui primazia à norma que, no caso concreto, mais proteja os interesses da pessoa em causa. Em outras palavras, por meio dele fica assegurado ao ser humano a aplicação da norma mais protetiva e mais garantidora de seus direitos, encontrada como resultado do "diálogo" travado entre as fontes no quadro de uma situação jurídica real. Esse exercício, capaz de encontrar um princípio geral que albergue os elementos normativos antitéticos, é papel que compete ao aplicador do direito" (MAZUOLLI, 2010, p. 204).

Assim, através do controle de convencionalidade poderá o Poder Judiciário intervir nas relações entre candidatos e Administração Pública, buscando aferir a compatibilidade da legislação interna com a Convenção Internacional sobre os Direitos das Pessoas com Deficiência. Sempre que um candidato pleitear sua participação no concurso público habilitando-se às vagas destinadas às pessoas com deficiência, por não constar no elenco das deficiências reconhecidas pela legislação interna, deverá o Juiz analisar o caso concreto pelos parâmetros que se intentou demonstrar neste artigo. Dessa forma, deverá considerar no caso concreto os princípios da máxima efetividade dos direitos fundamentais e da proporcionalidade no sentido de proibição da proteção insuficiente. No caso levado ao judiciário, não se anulará uma norma em face da outra, não podendo se falar em prevalência de uma sobre a outra, mas sim de diálogo e coordenação, buscando sempre aplicar o princípio pro homine, ou seja, a norma mais beneficia à pessoa no caso concreto.

Sem embargo, é importante frisar que a intervenção judicial deverá ser cautelosa e se embasar em prova pericial realizada nos moldes do Estatuto da Pessoa com Deficiência, ou seja, que busque aferir a deficiência por critério biopsicossocial e seja realizada sempre que possível por equipe multiprofissional e interdisciplinar, de forma a conferir racionalidade à intervenção judicial. Dessa forma, evita-se que a intervenção judicial ao invés de atender a igualdade material, promova mais desigualdade, quando se permitir o benefício de reserva de vagas a quem não se enquadra como pessoa com deficiência ou deixe de conferi-lo ao candidato que efetivamente necessita. 


\section{CONSIDERAÇÕES FINAIS}

Como se pode verificar, os tratados e convenções sobre direitos humanos representam uma reconfiguração na estrutura normativa do Estado brasileiro, uma vez que, enquanto normas materialmente constitucionais, podem integrar o "bloco de constitucionalidade" quando aprovados na forma do $\S 3^{\circ}$ do artigo $5^{\circ}$ da Constituição, ou ao menos possuírem o status de norma supralegal, estando acima da legislação infraconstitucional. De qualquer forma, servem como paradigma para verificar a validade na legislação interna.

No ordenamento jurídico tem-se incorporado relevante norma internacional de proteção dos direitos humanos. Trata-se da Convenção Internacional sobre os Direitos da Pessoa com Deficiência, que foi a primeira norma aprovada na forma do $\S 3^{\circ}$ do artigo $5^{\circ}$ da Constituição, sendo equivalente à emenda constitucional.

Essa Convenção traz um conceito abrangente de pessoa com deficiência, ao qual, além da deficiência em si, agrega-se o ambiente social e cultural no qual inserida a pessoa. Com isso, é possível constatar que as atuais definições de pessoa com deficiência prevista na legislação interna (Decreto 3.298/1999) não atendem de forma plena aos valores e princípios da Convenção, existindo possível antinomia normativa.

A questão da definição de pessoa com deficiência ganha especial relevo nos concursos públicos, uma vez que o ordenamento prevê reserva de vagas para esse grupo vulnerável. Assim, ante a incompletude da definição prevista na legislação interna, frequentemente o Poder Judiciário é instado a se manifestar, encontrando-se inclusive entendimentos sumulados pelos Tribunais Superiores, como, por exemplo, a Súmula 377 do Superior Tribunal de Justiça que entende que a visão monocular habilita o candidato a concorre às vagas destinadas às pessoas com deficiência, não obstante não constar como deficiência no Decreto 3.298/1999.

Assim, no caso concreto o Poder Judiciário pode verificar se certo candidato pode se beneficiar do benefício das vagas reservadas, quando sua deficiência não estiver nas definições de deficiência da legislação interna. Para tanto, deverá ser estabelecido o diálogo entre a Convenção sobre os Direitos das Pessoas com Deficiência e a legislação interna sempre privilegiando no caso concreto a norma mais favorável à pessoa, com análise a partir da hermenêutica constitucional embasada nos princípios da máxima efetividade dos direitos fundamentais e da proibição da proteção deficiente. 


\section{REFERÊNCIAS}

BARROSO, Luís Roberto. Interpretação e aplicação da Constituição: fundamentos de uma dogmática constitucional transformadora. 7. ${ }^{a}$ ed. rev. São Paulo: Saraiva, 2009.

DI PIETRO, Maria Sylvia Zanella. Direito Administrativo. 24. ed. São Paulo: Atlas, 2011.

DIREITO, Carlos Alberto Menezes. TRINDADE, Antônio Augusto Cançado. PEREIRA, Antônio Celso Alves (orgs.)Novas perspectivas do direito internacional contemporâneo Estudo em homenagem ao Professor Celso D. de Albuquerque Mello. Rio de Janeiro: Renovar, 2008.

FILHO, José dos Santos Carvalho. Manual de Direito Administrativo. 25. ed. ver., ampl. e atual. até a Lei no 12587, de 3-1-2012. - São Paulo: Atlas, 2012.

GUGEL, Maria Aparecida. Pessoas com deficiência e o direito ao concurso público: reserva de cargos e empregos públicos, administração pública direta e indireta. / Maria Aparecida Gugel _ Goiânia : Ed. da UCG, 2006. Disponível em: http://www.pessoacomdeficiencia.gov.br/app/sites/default/files/publicacoes/pcd-direitoconcurso-publico.pdf . Acesso em 10. mar. 2016.

JÚNIOR, Vidal Serrano Nunes (coord). MANUAL DE DIREITOS DIFUSOS. São Paulo: 2009. Editora: Verbatim, 2009.

MAZZUOLI, Valerio de Oliveira. Tratados internacionais de direitos humanos e direito interno - São Paulo: Saraiva, 2010.

MENDES, Gilmar Ferreira. BRANCO, Paulo Gustavo Gonet. Curso de Direito Constitucional. 10a .ed. ver. e atual. São Paulo: Saraiva, 2015.

NETO, Claudio Pereira de Souza. Daniel Sarmento. Direito Constitucional: teoria, história e métodos de trabalho. $2^{\text {a }}$.ed. Belo Horizonte: Fórum, 2014.

Novos Comentários à Convenção sobre os Direitos das Pessoas com Deficiência/Secretaria de Direitos Humanos da Presidência da República (SDH/PR)/Secretaria Nacional de Promoção dos Direitos da Pessoa com Deficiência (SNPD). Disponível

em http://www.pessoacomdeficiencia.gov.br/app/sites/default/files/publicacoes/convencao-sdpcdnovos-comentarios.pdf . acesso em 10/03/2016. Acesso em: 23. fev. 2016.

OLIVEIRA, RafaelCarvalho Rezende. PRINCÍPIOS DO DIREITO ADMINISTRATIVO. $2^{a}$. ed. São Paulo: Método, 2013.

PIOVESAN, Flávia. DIREITOS HUMANOS E O DIREITO CONSTITUCIONAL INTERNANCIONAL. 13 ${ }^{\text {a }}$ ed. São Paulo: Saraiva, 2012. 